\title{
The metabolism of "surplus" amino acids
}

\author{
David A. Bender* \\ Division of Biosciences and Division of Medical Education, University College London, Gower St, London WC1E 6BT, UK
}

(Submitted 27 July 2011 - Accepted 21 September 2011)

\section{Abstract}

For an adult in $\mathrm{N}$ balance, apart from small amounts of amino acids required for the synthesis of neurotransmitters, hormones, etc, an amount of amino acids almost equal to that absorbed from the diet can be considered to be "surplus" in that it will be catabolized. The higher diet-induced thermogenesis from protein than from carbohydrate or fat has generally been assumed to be due to increased protein synthesis, which is ATP expensive. To this must be added the ATP cost of protein catabolism through the ubiquitin-proteasome pathway. Amino acid catabolism will add to thermogenesis. Deamination results in net ATP formation except when serine and threonine deaminases are used, but there is the energy cost of synthesizing glutamine in extra-hepatic tissues. The synthesis of urea has a net cost of only $1.5 \times$ ATP when the ATP yield from fumarate metabolism is offset against the ATP cost of the urea cycle, but this offset is thermogenic. In fasting and on a low carbohydrate diet as much of the amino acid carbon as possible will be used for gluconeogenesis - an ATP-expensive, and hence thermogenic, process. Complete oxidation of most amino acid carbon skeletons also involves a number of thermogenic steps in which ATP (or GTP) or reduced coenzymes are utilized. There are no such thermogenic steps in the metabolism of pyruvate, acetyl CoA or acetoacetate, but for amino acids that are metabolized by way of the citric acid cycle intermediates there is thermogenesis ranging from 1 up to $7 \times$ ATP equivalent per mol.

\section{Key words: Amino acids: Catabolism: Thermogenesis}

\section{Introduction}

For an adult in $\mathrm{N}$ balance there will be an amount of amino acids to be catabolized equal to the dietary intake of protein, less faecal losses of undigested dietary protein, undigested endogenous proteins (including mucin in gastro-intestinal mucus, remnants of digestive enzymes and shed mucosal cells) and bacterial proteins. It is only in growth, pregnancy and recovery from tissue protein losses that there is a net increase in whole body protein, and even for someone in positive $\mathrm{N}$ balance there will be a considerable amount of amino acids to be catabolized because they are "surplus" to requirements for net protein synthesis.

It is well established that the diet-induced thermogenesis (DIT) associated with protein is considerably higher than that associated with carbohydrate or fat. Some 20-30\% of the energy consumed as protein is dissipated in DIT, compared with $5-10 \%$ of that from carbohydrate and $0-3 \%$ of that from fat ${ }^{(1,2)}$. Allowing for this thermic effect of protein suggests that the net metabolizable energy of protein is nearer $13 \mathrm{~kJ} / \mathrm{g}$ than the Atwater factor of $17 \mathrm{~kJ} / \mathrm{g}$. ${ }^{(3)}$

The thermic response to a high protein meal or diet (in longer-term studies) has been reported in many studies, some using liquid meals or diets and others meals or diets comprising normal foods, but designed to give different proportions of the macronutrients. Many such studies have used extreme proportions of protein, fat and carbohydrate. For example, Crovetti et al. ${ }^{(4)}$ fed three different isocaloric meals of ordinary foods to normal body weight women and measured heat output by indirect calorimetry over 7 hours. The meal providing $68 \%$ of energy from protein gave an increase in energy output of $261 \mathrm{~kJ}$, compared with $69 \%$ carbohydrate at $92 \mathrm{~kJ}$ and $70 \%$ fat at $97 \mathrm{~kJ}$. Dauncey \& Bingham ${ }^{(5)}$ fed diets providing $37 \%$ protein or $3 \%$ protein (replaced by sugars) and $48 \%$ fat, and measured total energy expenditure over $24 \mathrm{~h}$ in a respiratory chamber. The high protein diet led to a $12 \%$ increase in total energy expenditure, and significantly higher energy expenditure both in exercise and in sleeping. Each meal in this study was followed by a period of exercise, so it is difficult to disentangle the effects of feeding from those of exercise. Lejeune et al. ${ }^{(6)}$ demonstrated higher DIT, sleeping metabolic rate and activity-induced energy expenditure in subjects fed a high protein diet $30 \%$ energy from protein, $40 \%$ from carbohydrate and $30 \%$ from fat) than one providing an adequate intake of protein (10\% energy from protein, 60\% from carbohydrate and 30\% from fat). The increased thermogenesis associated with a high protein diet has been exploited in slimming regimens because of the need for increased fat metabolism to fuel the thermogenesis ${ }^{(3,7-10)}$. 
More than half of all patients undergoing surgery with general anaesthesia experience some degree of hypothermia, defined as a core body temperature below $35^{\circ} \mathrm{C}$. This can lead to cardiovascular and respiratory problems, impaired blood coagulation, and increased recovery time. Anaesthesia impairs central thermoregulation and lowers the threshold for vasoconstriction, so redistributing blood (and hence heat) to the periphery. At the same time, fluids are infused at room temperature rather than body temperature, and muscle relaxants inhibit shivering. ${ }^{(11)}$ The thermic effect of protein has been exploited to prevent post-operative hypothermia. Intravenous infusion of an amino acid mixture begun an hour before anaesthesia and continued throughout the period of surgery resulted in maintenance of rectal temperature at $37 \cdot 14^{\circ} \mathrm{C}$, while in patients receiving the same volume of saline, rectal temperature fell to $35.98^{\circ} \mathrm{C}^{(12)}$. The amino acid infusion was associated with increased pulmonary oxygen uptake. In patients undergoing coronary artery bypass surgery, infusion of an amino acid mixture for 2 hours from the start of surgery attenuated the fall in core body temperature (measured in the pulmonary artery) seen in patients receiving saline infusion, and led to a modest but significant progressive increase in body temperature during the remaining $4-6$ hours $^{(13)}$. Brundin and Wahren ${ }^{(14)}$ studied the effects of amino acid infusion in healthy volunteers; again there was an increase in body temperature by $0.25^{\circ} \mathrm{C}$ and energy expenditure (as determined by oxygen consumption). Half the increased oxygen consumption was by splanchnic tissues rather than muscle. In rats fed a high protein diet the concentrations of most amino acids reaching the periphery are lower than on a normal protein intake, reflecting the splanchnic extraction of amino acids, either for gluconeogenesis or catabolism. ${ }^{(15)}$

A number of mechanisms have been proposed to explain this thermic effect of protein: increased protein turnover, the energy cost of urea synthesis and gluconeogenesis from amino acids, and the relative inefficiency of the catabolism of amino acid carbon skeletons, as well as increased nonshivering thermogenesis as a result of increased activity of thermogenin.

\section{Increased protein turnover}

Protein synthesis is energy expensive. An adult human being synthesizes some $5.7 \mathrm{~g}$ of protein/ $\mathrm{kg}$ body weight/day, accounting for $18.8 \%$ of fasting metabolic rate or $12.9 \%$ of total energy expenditure ${ }^{(16)}$. For each amino acid incorporated in ribosomal protein synthesis there is a cost of $2 \times$ ATP equivalents to form aminoacyl tRNA (because the reaction yields AMP and pyrophosphate), plus $1 \times$ GTP (equivalent to ATP) and $1 \times$ ATP to move the growing peptide chain from the A site of the ribosome to the $\mathrm{P}$ site. This is a minimal cost of $4 \times$ ATP per amino acid incorporated or some $2.8 \mathrm{~kJ}$ per gram of protein synthesized. To this can be added the cost of active transport of amino acids into cells (an additional $0.8 \mathrm{~kJ} / \mathrm{gram}$ ) and synthesizing mRNA (an additional $0.6 \mathrm{~kJ} / \mathrm{g}$ ), giving a cost of some $4.2 \mathrm{~kJ} / \mathrm{g}$ of protein synthesized, or $20 \%$ of $\mathrm{BMR}^{(17)}$. Further costs of protein turnover include: (a) the relatively small cost of the action of the proof-reading site on aminoacyl tRNA synthetases, hydrolysing aminoacyl tRNA when the wrong amino acid has been incorporated, followed by re-esterification of the correct amino acid; (b) the ATP cost of ensuring correct folding of newly synthesized proteins by active chaperone proteins; (c) the energy cost of catabolizing incorrectly folded proteins, followed by resynthesis. This last will not be measured as protein turnover by conventional methods since incorrectly folded proteins are rapidly catabolized intracellularly.

Targeted protein catabolism via the ubiquitin-proteasome system is also ATP expensive, although the random hydrolysis of tissue proteins by lysosomes is not. Ubiquitin is a small (78 amino acid) protein that targets tissue proteins for uptake by the proteasome; it is not itself catabolized in the proteasome, but is recycled. However, there is apparently random mono-ubiquitination of proteins in the cell, followed by more specific attachment of three or four additional molecules of ubiquitin to those already present, catalysed by one of more than 600 ubiquitin ligases in the human genome. Each molecule of ubiquitin added involves an ATP cost $^{(18,19)}$. The proteasome is a large multi-enzyme complex that involves ATP-dependent de-ubiquitination of target proteins and ATP-dependent unfolding of the proteins to permit access by the proteases in the core of the proteasome. There are at least $6 \times$ ATPases involved in the proteasome ${ }^{(20)}$.

Robinson et al. ${ }^{(17)}$ measured energy expenditure and whole body protein turnover for 9 hours in a group of men fed hourly with flavoured water (i.e. fasting) or iso-energetic liquid diets providing either $70 \%$ carbohydrate or $70 \%$ protein and $15 \%$ fat. Compared with the fasting state, the high carbohydrate diet raised resting metabolic rate (RMR) by $5.7 \%$ (accounting for $5.7 \%$ of the energy intake) and the high protein diet by $23.5 \%$ (accounting for $9.6 \%$ of the energy intake). In the fasting state, protein synthesis was $87 \cdot 2 \mathrm{~g}$ over 9 hours, with catabolism of $110 \cdot 2 \mathrm{~g}$, giving $\mathrm{N}$ balance $=-23 \mathrm{~g}$; feeding the high carbohydrate diet gave protein synthesis of $131.2 \mathrm{~g}$, catabolism $109.8 \mathrm{~g}$, and $\mathrm{N}$ balance $=+21.4 \mathrm{~g}$; feeding the high protein diet gave protein synthesis of $243.9 \mathrm{~g}$, catabolism $78.9 \mathrm{~g}$ and $\mathrm{N}$ balance $=+165 \mathrm{~g}$. Based on a cost of $4.2 \mathrm{~kJ} / \mathrm{g}$ protein synthesized, they calculated that the cost of protein synthesis was $8.7 \%$ of total energy expenditure (TEE) in fasting, $11.7 \%$ of TEE after the high carbohydrate meals and $19 \cdot 8 \%$ of TEE after the high protein meals. After the high carbohydrate meals, protein synthesis accounted for $36 \%$ of the increased energy expenditure (with the remainder presumably the cost of glycogen synthesis); after the high protein meals, protein synthesis accounted for $68 \%$ of the increased energy expenditure. Since the high protein diet provided only $15 \%$ of energy from carbohydrate, is it likely that gluconeogenesis from amino acids accounted for a significant proportion of the increased energy expenditure. The decreased protein catabolism in response to feeding the high protein meals is in accordance with the observations of Garlick et $a l .{ }^{(21)}$ that the immediate response to feeding a high protein meal is a reduction in tissue protein catabolism, followed by a longer term adaptive response with increased synthesis and catabolism. 
Hochstenbach-Waelen et $a l .{ }^{(22)}$ fed subjects on iso-energetic diets providing 10 or $25 \%$ protein, 35 or $20 \%$ fat and $55 \%$ carbohydrate for 3 days, in a randomized crossover experiment, before they were placed in a respiration chamber for $36 \mathrm{~h}$. Twenty four hour TEE was $2 \cdot 5 \%$ higher, and the sleeping metabolic rate $4 \%$ higher, on the high protein diet. At $10 \%$ of energy from protein (casein) the subjects were unable to maintain $\mathrm{N}$ balance, but they were in positive $\mathrm{N}$ balance on the high protein diet. The high protein diet also led to negative fat balance.

Obviously, the positive $\mathrm{N}$ balance seen on feeding a high protein diet cannot continue; there must be adaptation of protein catabolism to match increased protein synthesis. Greig et al. ${ }^{(23)}$ maintained septic patients on total parenteral nutrition at $1.35 \times$ their RMR and either 191 or $366 \mathrm{mg} \mathrm{N} / \mathrm{kg}$ body weight/day. At the higher protein intake there was the expected increase in protein oxidation and oxygen consumption, and for the first 3 days the patients were in positive $\mathrm{N}$ balance. However, by days 5-6 the patients were back in $\mathrm{N}$ equilibrium. They also showed higher resting energy expenditure than those on the lower $\mathrm{N}$ intake.

Garlick et al. ${ }^{(21)}$ noted that in response to a high protein diet there is initially positive $\mathrm{N}$ balance, followed by an increased amplitude of cycling between protein synthesis in the fed state and protein catabolism in the fasting state, and suggested that amino acid oxidation accounts for up to $57 \%$ of TEE, compared with $21 \%$ on a high carbohydrate diet. However, only about half of the amino acids from a high protein diet were oxidized in their study. Price et al. ${ }^{(24)}$ similarly showed greater fasting $\mathrm{N}$ losses in fasting and gains in the fed state in subjects adapted for 12 days to diets providing $0.36,0 \cdot 77,1.59$ or $2 \cdot 31 \mathrm{~g}$ protein $/ \mathrm{kg}$ body weight, with overall negative $\mathrm{N}$ balance at the two lower levels of intake and overall positive $\mathrm{N}$ balance at the two higher levels. Harber et al. ${ }^{(25)}$ fed subjects a typical western diet (60\% carbohydrate, 30\% fat and 10\% protein) for two days, then an iso-energetic low-carbohydrate, highprotein diet for 7 days (5\% carbohydrate, $60 \%$ fat, $35 \%$ protein). They reported an increase in muscle protein fractional synthetic rate, but also an increase in whole body proteolysis as determined by the leucine reappearance rate.

Pannemans et al. ${ }^{(26,27)}$ fed young and elderly people diets providing $12 \%$ or $21 \%$ of energy from protein (at the expense of fat, with $46 \%$ of energy from carbohydrate) and measured $\mathrm{N}$ balance and protein turnover after adaptation to the diets for 3 weeks. The higher protein intake had no effect on $\mathrm{N}$ balance, which remained at zero, in the elderly subjects, but young adults showed positive $\mathrm{N}$ balance at the higher protein intake. Both protein synthesis and catabolism increased on feeding the high protein diet.

Millward \& Rivers ${ }^{(28)}$ proposed, initially on theoretical grounds, then confirmed by experimental data ${ }^{(29,30)}$ that there is (relatively slow) adaptation of amino acid catabolism in response to changes in protein intake. With increasing protein intake there is increased oxidation of dietary essential amino acids (especially the sulphur and branched chain amino acids and tryptophan) in both the fed and fasting states. In the fed state this is to remove (potentially toxic) amino acids that are present in excess of requirements for protein synthesis, but the catabolism continues in the fasting state because the key enzymes of amino acid catabolism have relatively long half-lives. This slow adaptation means that experimentally determined protein requirements will depend to a considerable extent on habitual protein intake. Even a period of 10-12 days may not be long enough to permit adaptation to a new level of protein intake.

\section{The energy cost of urea synthesis}

Examination of the urea synthesis cycle (Fig. 1) would suggest an energy cost of $4 \times$ ATP equivalents per mol of urea synthesized - the figure that is commonly quoted in textbooks. However, the fumarate that is released by the action of argininosuccinase is recycled back to oxaloacetate via reactions of the citric acid cycle, including malate dehydrogenase, then transaminated to aspartate that is used in the reaction catalysed by argininosuccinate synthetase. The reaction of malate dehydrogenase leads to reduction of $\mathrm{NAD}^{+}$to $\mathrm{NADH}$, which, in the mitochondrial electron transport chain yields approximately $2.5 \times$ ATP. This means that the net cost of the urea cycle per se is $1.5 \times$ ATP, but there is thermogenesis from the synthesis and utilization of $2.5 \times$ ATP.

There are four possible routes for the production of ammonia from amino acids:

(1) Glycine and L-amino acid oxidases catalyse a flavindependent reaction, and the resultant $\mathrm{FADH}_{2}$ is re-oxidized in the mitochondrial electron transport chain with a yield of approximately $1.5 \times$ ATP. Many amino acids undergo transamination linked to pyruvate as the amino acceptor, followed by transamination of the resultant alanine using glyoxylate as the amino acceptor, and oxidative deamination of the resultant glycine. The relative importance of this pathway is seen in primary hyperoxaluria (type I), where genetic defects of alanine-glyoxylate transaminase lead to massive accumulation of oxalate formed from glyoxylate. $^{(31)}$

(2) Transamination linked to 2-oxoglutarate as the amino acceptor yields glutamate. Glutamate dehydrogenase catalyses an $\mathrm{NAD}^{+}$dependent reaction, and the resultant $\mathrm{NADH}$ is re-oxidized in the mitochondrial electron transport chain with a yield of approximately $2.5 \times$ ATP.

(3) Transamination linked to oxaloacetate yields aspartate, which may either be used for synthesis of argininosuccinate and hence directly for urea synthesis (see Fig. 1), or for synthesis of AMP from IMP. As shown in Fig. 2, this reaction proceeds via the intermediate formation of adenylosuccinate at the expense of GTP (equivalent to $-1 \times$ ATP). However, the cleavage of adenylosuccinate to IMP releases fumarate, which is, as in urea synthesis, recycled back to aspartate, yielding $1 \times \mathrm{NADH}$, which is equivalent to $2.5 \times$ ATP. There is thus a net yield of $1.5 \times$ ATP when aspartate is the substrate for ammonia formation by this pathway. Again there is thermogenesis from the utilization of GTP. This adenine nucleotide cycle is especially important in deamination of amino acids in muscle, and in general tissues that have a high activity of 


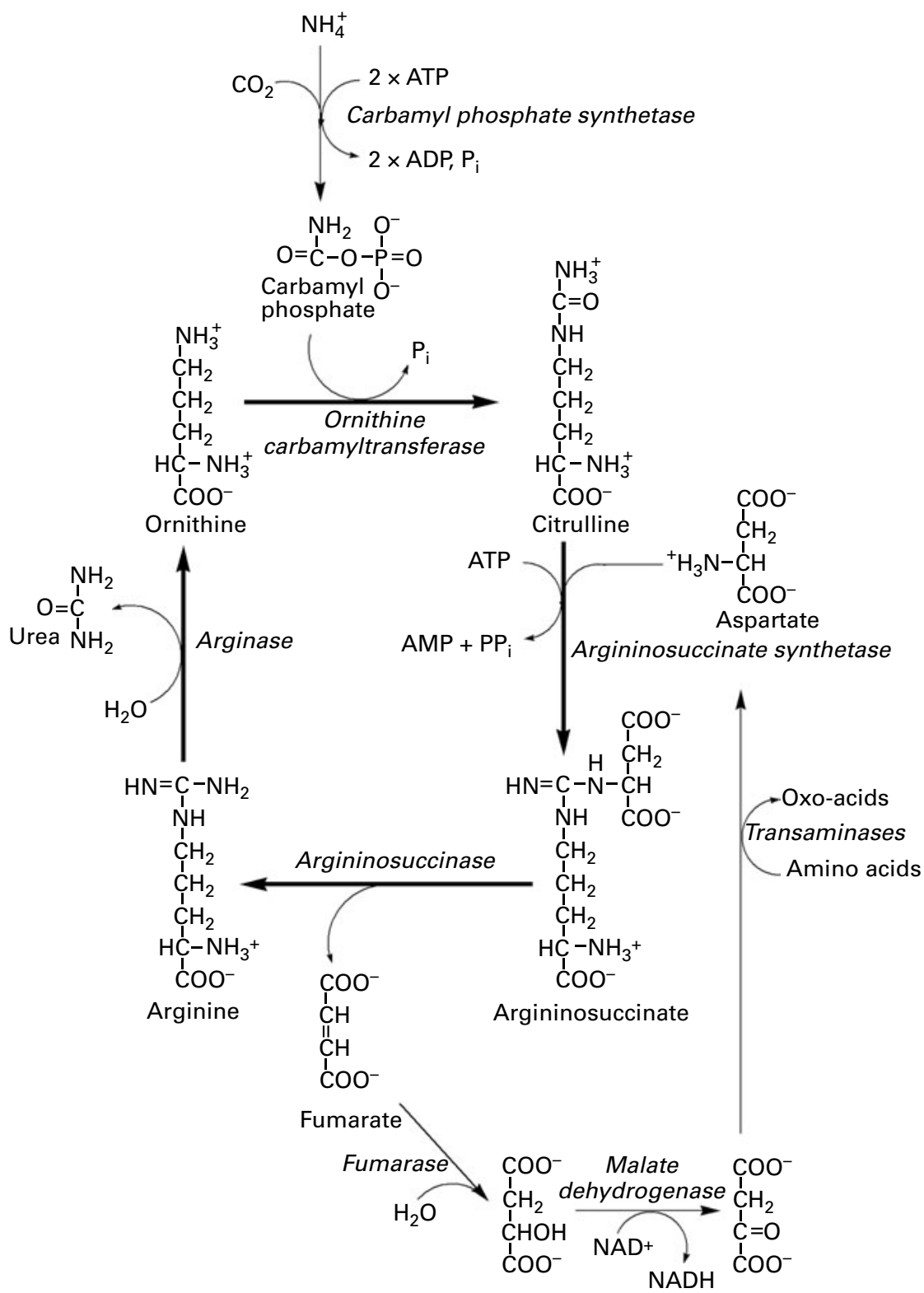

Fig. 1. The urea synthesis cycle and metabolism of fumarate to yield aspartate.

glutamate dehydrogenase have a low activity of adenosine deaminase, and vice versa. ${ }^{(32)}$

(4) Serine and threonine deaminases catalyse pyridoxal phosphate-dependent deamination with no reduction of any coenzymes, and hence no energy considerations.

This means that the synthesis of urea is thermogenic, with the utilization of $4 \times$ ATP that must be provided, but in most cases it is either ATP neutral or actually proceeds with a gain of ATP. When amino acids are deaminated by transamination linked to glyoxylate, followed by the action of glycine oxidase there is a yield of $1.5 \times$ ATP per $\mathrm{N}$, and the synthesis of urea is overall energetically neutral. When amino acids are transaminatively linked to 2-oxoglutarate or oxaloacetate, followed by the action of glutamate dehydrogenase (the urea synthesis cycle or the adenine nucleotide cycle), there is a yield of $2.5 \times$ ATP, and hence the synthesis of urea proceeds with a net yield of $+1 \times$ ATP.

Ammonium that is formed in extra-hepatic tissues is transported to the liver as glutamine. There is a cost of $1 \times$ ATP for each mol of glutamine synthesized, which will cancel out the ATP gain from ammoniagenesis via aspartate or glutamate. There is no yield of ATP when glutamine is hydrolysed by glutaminase to yield glutamate and ammonium. Ammonium is released from glutamine in the periportal cells of the liver, but then glutamine is synthesized in the perivenous cells to minimize the amount of ammonium entering the circulation. It is difficult to quantify the magnitude and energy cost of this catabolism and resynthesis of glutamine in the liver.

As much as $20-25 \%$ of the urea synthesized daily is either secreted into the small intestine in bile and pancreatic 


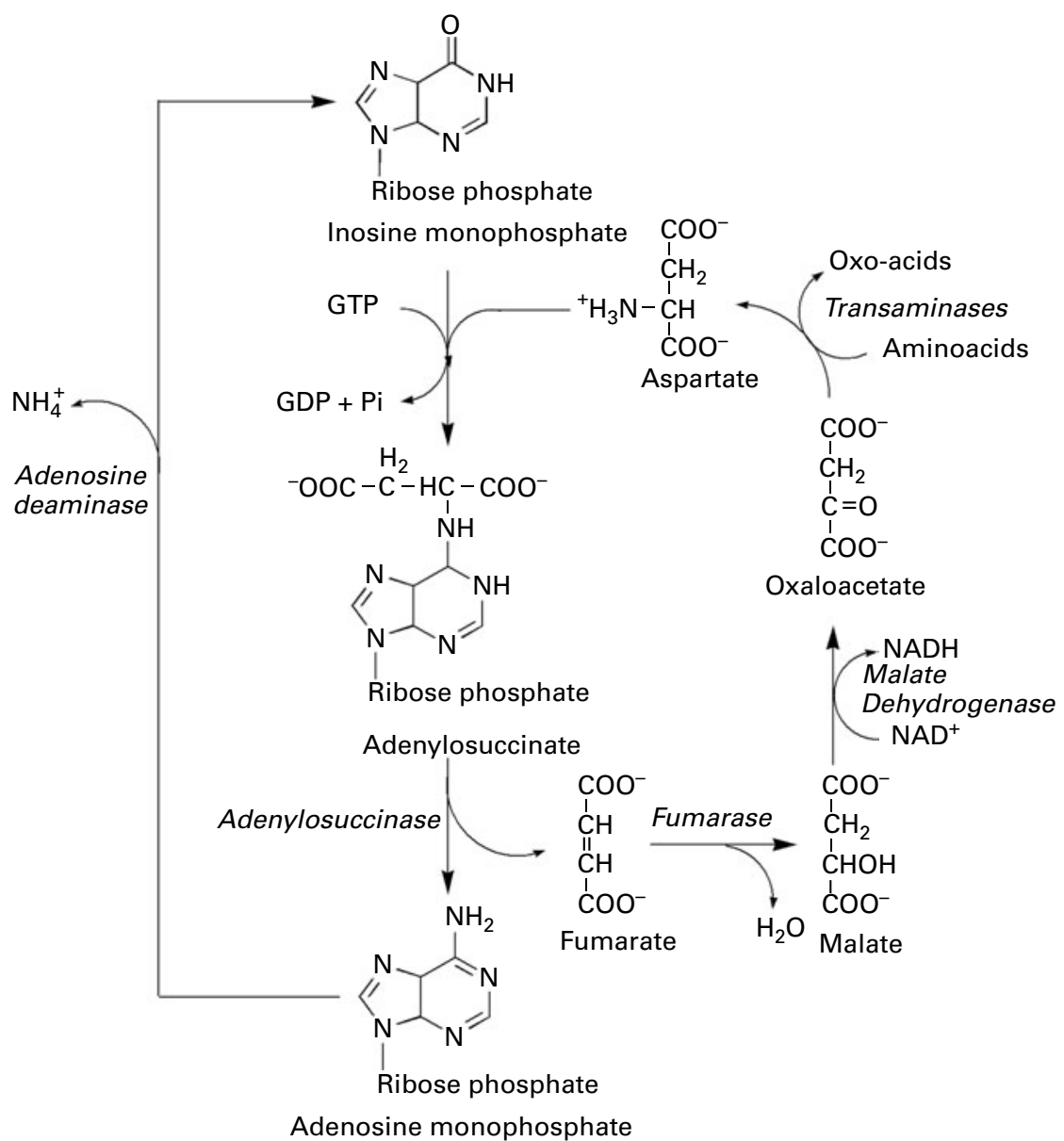

Fig. 2. Adenosine deaminase and the purine nucleotide cycle for ammoniagenesis from amino acids.

juice or diffuses across the intestinal wall, and is hydrolysed by intestinal bacteria. Some of the resultant ammonium is used for bacterial amino acid and protein synthesis, and some of these bacterial amino acids are absorbed, so that only about $10 \%$ of the nitrogen is lost in faeces. Most of the ammonium is absorbed and used in enterocytes or the liver for synthesis of urea (about 25\% of the ammonium released by intestinal bacteria), or, via glutamate dehydrogenase, synthesis of amino acids. ${ }^{(33-35)}$ Bacterial synthesis of amino acids will contribute to thermogenesis; resynthesis of urea will have a net cost of $1.5 \times$ ATP (with no offset from the formation of ammonium) and thermogenesis from the synthesis and utilization of $2.5 \times$ ATP. Reductive amination of 2-oxoglutarate to glutamate will have a cost of $-2.5 \times$ ATP.

\section{Gluconeogenesis and fatty acid synthesis from amino acids}

There is a clear need for gluconeogenesis from amino acid carbon skeletons in the fasting state, and also when a highprotein, low-carbohydrate diet is fed. Feeding rats a high protein diet ( $60 \%$ by weight) leads to depletion of glucogenic amino acids in blood, muscle and liver; switching to a low protein diet $(7.5 \%$ by weight) leads to accumulation of glucogenic amino acids. The response of alanine and glutamine is rapid, but that of threonine, serine and glycine is slower (7-11 days), reflecting the relatively long half-lives of the regulatory enzymes involved in their catabolism. ${ }^{(36)}$ Much of the gluconeogenesis from amino acids in rats fed a high protein diet is used to increase liver glycogen rather than being released into the circulation as free glucose; phosphoenolpyruvate carboxykinase activity is increased, but glucose 6-phosphatase activity is reduced. ${ }^{(37)}$

Bohé et al. ${ }^{(38)}$ found an immediate $19 \%$ increase in plasma glucose when control subjects were infused with an amino acid mixture, and plasma glucose remained elevated throughout the 9 hours of the infusion. Veldhorst et al. ${ }^{\text {(39) }}$ demonstrated increased gluconeogenesis in subjects fed a high-protein carbohydrate-free diet compared with a normal diet, and calculated that $42 \%$ of the increased energy expenditure after the high-protein diet was due to gluconeogenesis, and that the ATP cost of gluconeogenesis was 33\% of the ATP yield of glucose.

As shown in Fig. 3, for those amino acids that give rise to citric acid cycle intermediates (see Table 1), the cost of 


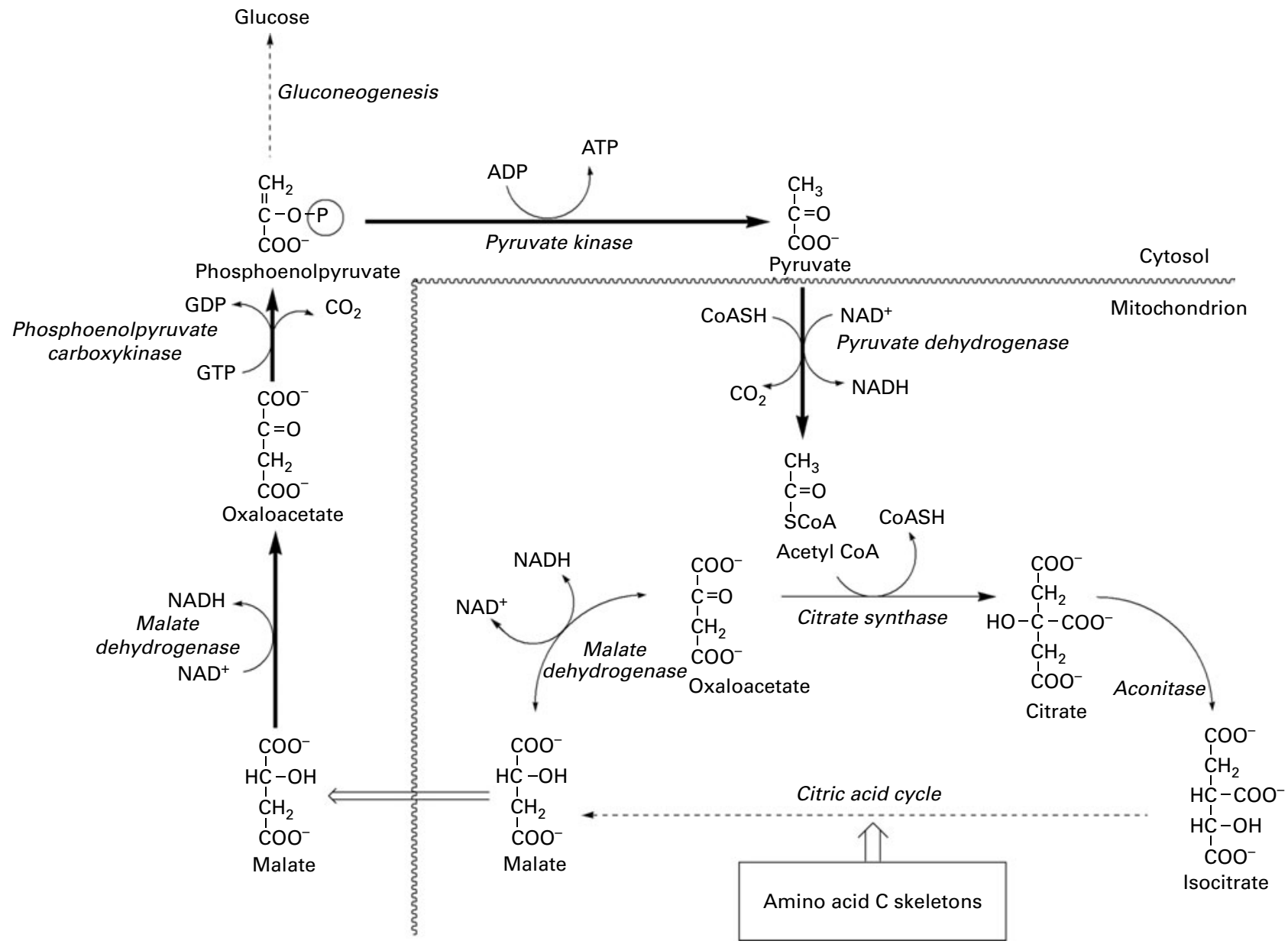

Fig. 3. Thermogenic steps in the oxidation of amino acid carbon skeletons that contribute citric acid cycle intermediates.

synthesizing glucose is $6 \times$ ATP equivalents per mol of glucose formed. The NADH needed in the cytosol for gluconeogenesis comes from the indirect export of oxaloacetate from the mitochondrion. In the mitochondrion oxaloacetate is reduced to malate, which is exported and oxidized to oxaloacetate in the cytosol. This formation and utilization of $\mathrm{NADH}$ can be considered to add $2.5 \times$ ATP equivalents to thermogenesis. For those amino acids that give rise to pyruvate there is an additional $1 \times$ ATP per mol of pyruvate $(2 \times$ ATP per mol of glucose formed) for the carboxylation of pyruvate to oxaloacetate.

In the fed state, if the resultant glucose 6-phosphate is isomerized to glucose 1-phosphate and used for glycogen synthesis in the liver there is an additional requirement of $1 \times$ UTP (equivalent to ATP) per mol. If glucose is released from the liver and used for glycogen synthesis in muscle then there is an additional requirement of $2 \times$ ATP equivalents per mol of glucose incorporated.

Table 1. Metabolic fates of the carbon skeletons of amino acids

\begin{tabular}{lll}
\hline & Glucogenic intermediates & Ketogenic intermediates \\
\hline Alanine & Pyruvate & - \\
Glycine $\rightarrow$ serine & Pyruvate & - \\
Cysteine & Pyruvate & - \\
Tryptophan & Pyruvate & acetyl CoA \\
Arginine & 2-Oxoglutarate & - \\
Glutamine $\rightarrow$ glutamate & 2-Oxoglutarate & - \\
Proline $\rightarrow$ glutamate & 2-Oxoglutarate & - \\
Histidine $\rightarrow$ glutamate & 2-Oxoglutarate & - \\
Methionine & Propionyl CoA & - \\
Isoleucine & Propionyl CoA & acetyl CoA \\
Valine & Succinyl CoA & - \\
Asparagine $\rightarrow$ aspartate & Oxaloacetate or fumarate & - \\
Phenylalanine $\rightarrow$ tyrosine & Fumarate & acetoacetate \\
Leucine & - & acetoacetate and acetyl CoA \\
Lysine & - & acetyl CoA \\
\hline
\end{tabular}


If the carbon skeletons of amino acids other than those that yield pyruvate, acetyl CoA or acetoacetate are to be used for fatty acid synthesis then again there is the GTP cost of synthesizing phosphoenolpyruvate and then pyruvate from oxaloacetate to be subtracted from the ATP yield of the oxidative decarboxylation of pyruvate to acetyl CoA.

\section{The efficiency of amino acid catabolism}

The citric acid cycle is generally considered to provide a pathway for the complete oxidation of amino acid carbon skeletons. This is clearly so for amino acids that yield pyruvate, acetyl CoA or acetoacetate (Table 1). However, for amino acids that provide intermediates of the citric acid cycle, the cycle does not, per se, permit complete oxidation because increasing the amount of any one of the intermediates of the cycle will, unless intermediates are withdrawn for synthesis of other metabolites, result in an increase in the amount of oxaloacetate over and above that which is required to maintain cycle activity.

For complete oxidation, this excess oxaloacetate must be reduced to malate, exported from the mitochondrion into the cytosol, oxidized to oxaloacetate and then undergo phosphorylation (at the expense of GTP) and decarboxylation to phosphoenolpyruvate, followed by the pyruvate kinase reaction to yield pyruvate and ATP. This sequence of reactions is therefore thermogenic, with consumption of GTP and formation of ATP.

As discussed above, when the malate exported from the mitochondrion is used for gluconeogenesis, the NADH formed in the oxidation of malate to oxaloacetate is used for the reduction of bisphosphoglycerate. If the oxaloacetate is used for synthesis of pyruvate to re-enter the mitochondrion for complete oxidation then the cytosolic NADH is not used.
The malate-aspartate shuttle to transfer reducing equivalents from the cytosol into the mitochondrion obviously cannot be used, since it depends on reduction of oxaloacetate to malate in the cytosol and transport of malate into the mitochondrion for re-oxidation - the reverse of the sequence of reactions involved in transporting oxaloacetate out of the mitochondrion for pyruvate synthesis. Therefore the glycerophosphate shuttle must be used. This involves cytosolic reduction of dihydroxyacetone phosphate to glycerol 3-phosphate at the expense of $\mathrm{NADH}$, with mitochondrial oxidation back to dihydroxyacetone phosphate at the expense of FAD being reduced. This involves a net loss of $1 \times$ ATP equivalent, since NADH yields $2.5 \times$ ATP in the mitochondrial electron transport chain, while reduced flavins yield only $1.5 \times$ ATP.

Tracing the pathways for catabolism and complete oxidation to carbon dioxide and water of the carbon skeletons of the amino acids permits calculation of the total ATP yield. A number of authors ${ }^{(40-43)}$ have performed such calculations in order to calculate the energy yield of protein to achieve more accurate figures than the generally used Atwater factor of $17 \mathrm{~kJ} / \mathrm{g}$. Table 2 shows a recalculation of the total ATP yield and the ATP (or reduced coenzyme) cost of amino acid catabolism (as appropriate with different values for alternative pathways), assuming that reduced nicotinamide nucleotide coenzymes are equivalent to $2.5 \times$ ATP and reduced flavins to $1.5 \times$ ATP. $^{(44)}$

The difference between the total ATP yield and the ATP plus reduced coenzyme requirement for catabolism is the net yield of ATP per mol of amino acid catabolized. The ATP- or $\mathrm{NAD}(\mathrm{P}) \mathrm{H}$-utilizing steps can be considered as contributing to thermogenesis, and hence the thermic effect of protein. The consumption of ATP or reduced coenzymes can be considered to be equivalent to "unproductive" or wasteful thermogenesis. There is no such unproductive thermogenesis for alanine,

Table 2. ATP yield and thermogenesis from amino acid carbon skeleton oxidation

\begin{tabular}{|c|c|c|c|c|c|c|c|c|}
\hline & $\begin{array}{l}\text { Gain } \\
\text { ATP }\end{array}$ & $\begin{array}{c}\text { Gain } \\
\mathrm{NAD}(\mathrm{P}) \mathrm{H}\end{array}$ & $\begin{array}{l}\text { Gain } \\
\text { FADH }\end{array}$ & $\begin{array}{c}\text { Gain } \\
\text { ATP equivalents }\end{array}$ & $\begin{array}{c}\text { Consumed } \\
\text { ATP }\end{array}$ & $\begin{array}{l}\text { Consumed } \\
\text { NAD(P)H }\end{array}$ & $\begin{array}{c}\text { Gain } \\
\text { net ATP }\end{array}$ & $\begin{array}{l}\text { Thermogenesis } \\
\text { ATP equivalents }\end{array}$ \\
\hline Alanine & 1 & 4 & 1 & $12 \cdot 5$ & 0 & 0 & $12 \cdot 5$ & 0 \\
\hline Arginine & 3 & 8 & 2 & 26 & 1 & 0 & 25 & 1 \\
\hline Asparagine & 2 & 4 & 1 & $13 \cdot 5$ & 1 & 0 & $12 \cdot 5$ & 1 \\
\hline Aspartate & 2 & 4 & 1 & $13 \cdot 5$ & 1 & 0 & $12 \cdot 5$ & 1 \\
\hline Cysteine via pyruvate & 1 & 4 & 1 & $12 \cdot 5$ & 0 & 0 & $12 \cdot 5$ & 0 \\
\hline Cysteine via taurine & 0 & 0 & 2 & 3 & 0 & 0 & 3 & 0 \\
\hline Glutamate & 3 & 7 & 2 & 23.5 & 1 & 0 & $22 \cdot 5$ & 1 \\
\hline Glutamine & 3 & 7 & 2 & 23.5 & 1 & 0 & $22 \cdot 5$ & 1 \\
\hline Glycine via glyoxylate & 0 & 0 & 0 & 0 & 0 & 1 & -2.5 & $2 \cdot 5$ \\
\hline $2 \times$ glycine via serine & 1 & 4 & 1 & $12 \cdot 5$ & 0 & 0 & $12 \cdot 5$ & 0 \\
\hline Histidine & 3 & 7 & 2 & 23.5 & 1 & 0 & $22 \cdot 5$ & 1 \\
\hline Isoleucine & 4 & 11 & 3 & 36 & 2 & 0 & 34 & 2 \\
\hline Leucine & 3 & 11 & 3 & 35 & 2 & 0 & 33 & 2 \\
\hline Lysine via pipecolic acid & 1 & 7 & 4 & 24.5 & 2 & 0 & $22 \cdot 5$ & 2 \\
\hline Lysine via saccharopine & 1 & 7 & 2 & 21.5 & 2 & 1 & 17 & $4 \cdot 5$ \\
\hline Methionine, Cys via Tau & 3 & 6 & 3 & $22 \cdot 5$ & 2 & 0 & $20 \cdot 5$ & 2 \\
\hline Methionine, Cys via pyruvate & 4 & 10 & 3 & 33.5 & 2 & 0 & $31 \cdot 5$ & 2 \\
\hline Phenylalanine & 4 & 11 & 3 & 36 & 2 & 2 & 29 & 7 \\
\hline Proline & 3 & 9 & 2 & $28 \cdot 5$ & 1 & 0 & $27 \cdot 5$ & 1 \\
\hline Serine & 1 & 4 & 1 & $12 \cdot 5$ & 0 & 0 & $12 \cdot 5$ & 0 \\
\hline Threonine & 1 & 6 & 2 & 19 & 0 & 0 & 19 & 0 \\
\hline Tryptophan & 3 & 12 & 3 & 37.5 & 0 & 0 & 37.5 & 0 \\
\hline Tyrosine & 4 & 11 & 3 & 36 & 2 & 1 & 31.5 & 4.5 \\
\hline Valine & 3 & 9 & 2 & 28.5 & 1 & 0 & 27.5 & 1 \\
\hline
\end{tabular}


cysteine, serine (or glycine metabolized via glyoxylate), threonine and tryptophan. For most other amino acids there is unproductive thermogenesis of 1 or $2 \times$ ATP; catabolism of lysine metabolized by way of saccharopine and of tyrosine involves $4.5 \times$ ATP equivalents of thermogenesis and catabolism of phenylalanine $7 \times$ ATP equivalents.

\section{Uncoupling of mitochondrial electron transport and oxidative phosphorylation}

Petzke et al. ${ }^{(45)}$ fed rats ad libitum on three levels of protein: $13.8 \%$ by weight of the diet (appropriate for rats), $25.7 \%$ or $51.3 \%$. The animals on the highest protein intake had a higher food consumption than those on the appropriate or intermediate protein intake. Animals fed both the higher protein intakes gained less weight over 8 weeks, had smaller epididymal fat pads and had a lower gain in body weight/MJ consumed. They attributed this to increased expression of uncoupling protein (UCP) mRNA in liver (at the intermediate protein intake, with no further increase at the highest protein intake) and brown adipose tissue (increased at the highest protein intake but not the intermediate level). The authors noted that increased mRNA might or might not translate into increased uncoupling protein synthesis. However, Hurtaud et al. ${ }^{(46)}$ showed that physiological concentrations of glutamine specifically increase translation of uncoupling protein mRNA in isolated colonocytes, macrophages (both of which utilize glutamine as a major metabolic fuel) and pancreatic $\beta$-islet cells (which do not), despite a modest fall in mRNA. The effect was specific for glutamine, with no other amino acid leading to increased UCP synthesis (phenylalanine alone led to reduced UCP synthesis) and no other amino acid having a significant synergistic effect when added together with glutamine.

Rats fed a high protein diet have less interscapular brown adipose tissue than those fed a lower protein intake whether they are maintained at $22^{\circ} \mathrm{C}$ or $6^{\circ} \mathrm{C} .{ }^{(47)}$. This may explain the increased expression of uncoupling proteins in response to a high protein $\operatorname{diet}^{(31,32)}$ - an attempt to maintain thermogenesis with less brown adipose tissue. There is no reason why it should be desirable for protein oxidation to be less energetically efficient than oxidation of fat or carbohydrate. Stock $^{(48)}$ has suggested that DIT, presumably as a result of uncoupling rather than the ATP requirements of metabolic pathways, evolved as a mechanism to deal with nutrientdeficient or unbalanced diets and that the role of DIT in the regulation of energy balance is secondary to its function in regulating the metabolic supply of essential nutrients.

One possible role of UCP is in regulation of fatty acid metabolism. Transport of fatty acids into the mitochondrion is regulated by the carnitine acyltransferases at the outer and inner faces of the mitochondrial membranes, and the fact that the acyl carnitine transporter will only carry acyl carnitine into the mitochondrion in exchange for free carnitine being exported. ${ }^{(49,50)}$ However, free fatty acids may also enter the mitochondrion by dissolving in the lipid membrane and flipping across, bypassing the regulated system. It has been suggested that the role of UCP is to transport these free fatty acids, present in amounts in excess of requirements for oxidation, back across the mitochondrial membrane. This involves proton flux across the membrane, and hence effectively partially uncouples electron transport from ADP phosphorylation. This will be thermogenic since there is now oxidation of metabolic fuels to provide protons that are not used to drive ATP synthesis.

It is probably impossible to quantify uncoupling in vivo. It is possible to measure carbon and nitrogen fluxes, oxygen consumption and heat output, but not turnover of ATP in the whole body, although this is possible with isolated cells and perfused organs using ${ }^{31} \mathrm{P}$ nuclear magnetic resonance. ${ }^{(51)}$

\section{Conclusions}

While much of the thermogenesis associated with protein intake can be attributed to increased protein synthesis and catabolism (both of which are ATP expensive), ammoniagenesis offsets the ATP cost of urea synthesis, but results in thermogenesis. Gluconeogenesis from amino acid carbon skeletons is ATP expensive, and oxidation of most amino acid carbon skeletons involves consumption of ATP and reduced coenzymes, so adding to thermogenesis.

\section{Acknowledgements}

No conflicts of interest declared. This work received no specific grant from any funding agency in the public, commercial or not-for-profit sectors. The author's conference fees and travel expenses were paid by the conference organisers.

\section{References}

1. Tappy L (1996) Thermic effect of food and sympathetic nervous system activity in humans. Reprod Nutr Dev 36, 391-397.

2. Jequier E (2002) Pathways to obesity. Int J Obes Relat Metab Disord 26, Suppl. 2, S12-S17.

3. Westerterp-Plantenga MS (2008) Protein intake and energy balance. Regul Pept 149, 67-69.

4. Crovetti R, Porrini M, Santangelo A, et al. (1998) The influence of thermic effect of food on satiety. Eur J Clin Nutr 52, 482-488.

5. Dauncey MJ \& Bingham SA (1983) Dependence of $24 \mathrm{~h}$ energy expenditure in man on the composition of the nutrient intake. Br J Nutr 50, 1-13.

6. Lejeune MP, Westerterp KR, Adam TC, et al. (2006) Ghrelin and glucagon-like peptide 1 concentrations, 24-h satiety, and energy and substrate metabolism during a high-protein diet and measured in a respiration chamber. Am J Clin Nutr 83, 89-94.

7. Halton TL \& Hu FB (2004) The effects of high protein diets on thermogenesis, satiety and weight loss: a critical review. J Am Coll Nutr 23, 373-385.

8. Hu FB (2005) Protein, body weight, and cardiovascular health. Am J Clin Nutr 82, Suppl. 1, 242S-247S.

9. Eisenstein J, Roberts SB, Dallal G, et al. (2002) High-protein weight-loss diets: are they safe and do they work? A review of the experimental and epidemiologic data. Nutr Rev $\mathbf{6 0}$, (7 Pt 1), 189-200.

10. Westerterp-Plantenga MS, Rolland V, Wilson SA, et al. (1999) Satiety related to $24 \mathrm{~h}$ diet-induced thermogenesis during 
high protein/carbohydrate vs high fat diets measured in a respiration chamber. Eur J Clin Nutr 53, 495-502.

11. ASPAN (American Society for PeriAnesthetic Nursing) (2001) Clinical guideline for the prevention of unplanned perioperative hypothermia. J PeriAnesth Nursing 16, 305-314.

12. Sellden E, Branstrom R \& Brundin T (1996) Preoperative infusion of amino acids prevents postoperative hypothermia. BrJ Anaesth 76, 227-234.

13. Moriyama T, Tsuneyoshi I, Omae T, et al. (2008) The effect of amino-acid infusion during off-pump coronary arterial bypass surgery on thermogenic and hormonal regulation. J Anesth 22, 354-360.

14. Brundin T \& Wahren J (1994) Effects of i.v. amino acids on human splanchnic and whole body oxygen consumption, blood flow, and blood temperatures. Am J Physiol 266, (3 Pt 1), E396-E402.

15. Morens C, Gaudichon C, Fromentin G, et al. (2001) Daily delivery of dietary nitrogen to the periphery is stable in rats adapted to increased protein intake. Am J Physiol Endocrinol Metab 281, E826-E836.

16. Waterlow JC, Garlick PJ \& Millward DJ (1978) Protein turnover in mammalian tissues and the whole body. Amsterdam: North-Holland.

17. Robinson SM, Jaccard C, Persaud C, et al. (1990) Protein turnover and thermogenesis in response to high-protein and high-carbohydrate feeding in men. Am J Clin Nutr 52, $72-80$.

18. Deshaies RJ \& Joazeiro CA (2009) RING domain E3 ubiquitin ligases. Annu Rev Biochem 78, 399-434.

19. Reyes-Turcu FE, Ventii KH \& Wilkinson KD (2009) Regulation and cellular roles of ubiquitin-specific deubiquitinating enzymes. Annu Rev Biochem 78, 363-397.

20. Finley D (2009) Recognition and processing of ubiquitinprotein conjugates by the proteasome. Annu Rev Biochem 78, 477-513.

21. Garlick PJ, McNurlan MA \& Patlak CS (1999) Adaptation of protein metabolism in relation to limits to high dietary protein intake. Eur J Clin Nutr 53, Suppl. 1, S34-S43.

22. Hochstenbach-Waelen A, Veldhorst MA, Nieuwenhuizen AG, et al. (2009) Comparison of 2 diets with either $25 \%$ or $10 \%$ of energy as casein on energy expenditure, substrate balance, and appetite profile. Am J Clin Nutr 89, 831-838.

23. Greig PD, Elwyn DH, Askanazi J, et al. (1987) Parenteral nutrition in septic patients: effect of increasing nitrogen intake. Am J Clin Nutr 46, 1040-1047.

24. Price GM, Halliday D, Pacy PJ, et al. (1994) Nitrogen homeostasis in man: influence of protein intake on the amplitude of diurnal cycling of body nitrogen. Clin Sci (Lond) 86, 91-102.

25. Harber MP, Schenk S, Barkan AL, et al. (2005) Effects of dietary carbohydrate restriction with high protein intake on protein metabolism and the somatotropic axis. I Clin Endocrinol Metab 90, 5175-5181.

26. Pannemans DL, Halliday D \& Westerterp KR (1995) Wholebody protein turnover in elderly men and women: responses to two protein intakes. Am J Clin Nutr 61, 33-38.

27. Pannemans DL, Halliday D, Westerterp KR, et al. (1995) Effect of variable protein intake on whole-body protein turnover in young men and women. Am J Clin Nutr 61, 69-74.

28. Millward DJ \& Rivers JP (1988) The nutritional role of indispensable amino acids and the metabolic basis for their requirements. Eur J Clin Nutr 42, 367-393.
29. Millward DJ (1998) Metabolic demands for amino acids and the human dietary requirement: Millward and Rivers (1988) revisited. J Nutr 128, Suppl. 12, 2563S-2576S

30. Millward DJ (2003) An adaptive metabolic demand model for protein and amino acid requirements. Br J Nutr $\mathbf{9 0}$, 249-260.

31. Danpure CJ (2004) Molecular aetiology of primary hyperoxaluria type 1. Nephron Exp Nephrol 98, e39-e44.

32. Lowenstein JM (1972) Ammonia production in muscle and other tissues: the purine nucleotide cycle. Physiol Rev 52, 382-414.

33. Long CL, Jeevanandam M \& Kinney JM (1978) Metabolism and recycling of urea in man. Am J Clin Nutr 31, 1367-1382.

34. Jackson AA (1995) Salvage of urea-nitrogen and protein requirements. Proc Nutr Soc 54, 535-547.

35. Bergen WG \& Wu G (2009) Intestinal nitrogen recycling and utilization in health and disease. J Nutr 139, 821-825.

36. Moundras C, Remesy C \& Demigne C (1993) Dietary protein paradox: decrease of amino acid availability induced by high-protein diets. Am J Physiol 264, (6 Pt 1), G1057-G1065.

37. Azzout-Marniche D, Gaudichon C, Blouet C, et al. (2007) Liver glyconeogenesis: a pathway to cope with postprandial amino acid excess in high-protein fed rats? Am J Physiol Regul Integr Comp Physiol 292, R1400-R1407.

38. Bohe J, Low JF, Wolfe RR, et al. (2001) Latency and duration of stimulation of human muscle protein synthesis during continuous infusion of amino acids. J Physiol 532 (Pt 2), $575-579$

39. Veldhorst MA, Westerterp-Plantenga MS \& Westerterp KR (2009) Gluconeogenesis and energy expenditure after a high-protein, carbohydrate-free diet. Am J Clin Nutr 90, 519-526.

40. Livesey G (1984) The energy equivalents of ATP and the energy values of food proteins and fats. Br J Nutr 51, 15-28.

41. van Milgen J (2002) Modeling biochemical aspects of energy metabolism in mammals. J Nutr 132, 3195-3202.

42. Ferrer-Lorente R, Fernandez-Lopez JA \& Alemany M (2007) Estimation of the metabolizable energy equivalence of dietary proteins. Eur J Nutr 46, 1-11.

43. Birkett S \& de Lange K (2001) A computational framework for a nutrient flow representation of energy utilization by growing monogastric animals. Br J Nutr 86, 661-674.

44. Hinkle PC (2005) $\mathrm{P} / \mathrm{O}$ ratios of mitochondrial oxidative phosphorylation. Biochim Biophys Acta 1706, 1-11.

45. Petzke KJ, Friedrich M, Metges CC, et al. (2005) Long-term dietary high protein intake up-regulates tissue specific gene expression of uncoupling proteins 1 and 2 in rats. Eur J Nutr 44, 414-421.

46. Hurtaud C, Gelly C, Chen Z, et al. (2007) Glutamine stimulates translation of uncoupling protein 2 mRNA. Cell Mol Life Sci 64, 1853-1860.

47. Harri M \& Brockway JM (1985) Effect of dietary protein concentration and ambient temperature on the energy, protein and water metabolism of the rat. BrJ Nutr 53, 363-372.

48. Stock MJ (1999) Gluttony and thermogenesis revisited. Int J Obes Relat Metab Disord 23, 1105-1117.

49. Kerner J \& Hoppel C (2000) Fatty acid import into mitochondria. Biochim Biophys Acta 1486, 1-17.

50. Eaton S (2002) Control of mitochondrial beta-oxidation flux. Prog Lipid Res 41, 197-239.

51. Gadian DG \& Radda GK (1981) NMR studies of tissue metabolism. Annu Rev Biochem 50, 69-83. 